Vol. XXIII No $3 \quad 2017$

\title{
MAINTENANCE SYSTEM RESEARCH FOR ARMORED VEHICLES IN PEACEKEEPING OPERATION AS CLOSE QUEUEING SYSTEM IN DYNAMIC REGIME
}

\author{
Iliyan LILOV, Ivan GEORGIEV \\ "Vasil Levski" National Military University, Veliko Tarnovo, Bulgaria \\ inlilov@nvu.bg, iygeorgiev@nvu.bg
}

\begin{abstract}
The maintenance system for wheel vehicles of 4th infantry battalion from Iraqi stable forces is studied in this article as a close queuing system. The differential equations of the dynamic functioning of the system are derived and solved numerically. The results of the dynamic characteristics and loading of the system are analyzed and compared with the results in stationary regime.
\end{abstract}

Keywords: Queuing model; maintenance.

\section{Introduction}

The conditions and procedures for participation of units of the Bulgarian army in peacekeeping operations are regulated in the Constitution of the Republic of Bulgaria and the Law on defence and armed forces.

The troops participating in these missions are armed with permanent technical equipment on the Bulgarian side and assigned technical equipment on the part of our coalition partners.

The paper aims to study the process of operation, service and repair of permanent technical equipment, as well as the daily maintenance of assigned technical equipment by the crews and the company for logistical support. The system for service and repair, as any military structure, shall be regarded as a closed system of queuing system due to the final number of orders and the inability to deal with those orders at another location [2,3,5].

The flawless and efficient functioning of the system for technical maintenance is a prerequisite for minimising vehicle failures [3]. In view of studying this system, the mathematical apparatus of the theory of queuing is applied. The subject of the survey is the division of the logistical support unit which carries out servicing and repair operations on vehicles. The input into the system is a random, statistically received flow of orders for daily or phased service and repair of separate machines which have been placed at different moments in time [7].

A check of the workload of the system and its performance has been carried out in this publication. The data on the operation, service and repair of vehicles has been collected from the documentation of Section S-4 of 4th infantry battalion of the stabilization forces in the Republic of Iraq, and it include the following:

- Monthly travel records of armoured vehicles;

- Logbook for the receipt of material resources for repair.

\section{Input-output characteristics of queuing system.}

The input-output characteristics of the queuing system are $[2,3,5,7]$ :

- Intensity of the input flow $-\lambda$; 
- $\quad$ Tiem for servicing the orders $-t_{o б c}$;

- Number of channels (the division for servicing and repair) $-m=6$ pcs.;

- Maximum number of orders (number of employed machines for the research period) $-n=83$ pcs.
To determine $\lambda$ the statistical data on the conducted repair and servicing operations recorded in table 1 have been used.

Table1 Statistical data on a system for technical servicing of vehicles

\begin{tabular}{|c|c|c|c|c|}
\hline Type of vehicle & $\begin{array}{c}\text { Number of repairs } \\
{[4]}\end{array}$ & $\begin{array}{c}\text { Technical Servicing } \\
\text { first/second degree } \\
{[4,6,8]}\end{array}$ & $\begin{array}{c}\text { Daily Technical } \\
\text { Servicing (DTS) } \\
{[6,8]} \\
\end{array}$ & $\begin{array}{l}\text { Total number of } \\
\text { orders }\end{array}$ \\
\hline ZIL-131 & 202 & 23 & 806 & 1031 \\
\hline$\ldots \ldots \ldots \ldots$ & & … & 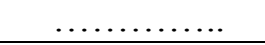 & 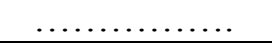 \\
\hline HUMMER & 29 & 0 & 590 & 619 \\
\hline$\Sigma$ & 400 & 37 & 2740 & 3177 \\
\hline
\end{tabular}

As regards the number of vehicle failures (machines for servicing and repair) per unit time per average number of machines in full operational order over a given period of time $\Delta \mathbf{t}[7]$.

$$
\hat{\lambda}(t)=\frac{n(\Delta t)}{N_{c p} \Delta t}=0,369
$$

Where $n(t)$ - is $\Sigma$ of all orders per unit time over the research period; $N_{c p}=\frac{\left(N_{i}+N_{i+1}\right)}{2}$ is the average number of

Table 2 Statistical data on a system for technical servicing of vehicles

\begin{tabular}{|c|c|c|c|}
\hline Type of vehicle & Number of repairs & $\begin{array}{l}\text { Time for completing the } \\
\text { tasks }\end{array}$ & $\begin{array}{c}\text { Number of orders per } \\
\text { time unit }\end{array}$ \\
\hline & $\mathrm{N}_{\mathrm{i}}$ & $h_{i}$ & $\mathrm{~N}_{\mathrm{i}} \cdot \mathrm{h}_{\mathrm{i}}$ \\
\hline ZIL-131-DTS & 806 & 1,3 & 1047,8 \\
\hline ........... & $\ldots \ldots \ldots \ldots$ & $\ldots \ldots \ldots \ldots$ & $\ldots \ldots \ldots \ldots$ \\
\hline HUMMER -DTS & 590 & 1,3 & 767 \\
\hline ............ & ........... & ............. & ............ \\
\hline$\Sigma$ & 3359 & & 6640,4 \\
\hline
\end{tabular}

The length of servicing one order $t_{\text {обс. }}$ is defined by applying formula (2), whereas the intensity of the servicing $\mu$-by applying (3) [5]:

$t_{\text {cp.oбc. }}=\frac{\sum\left(N_{i} \cdot h_{i}\right)}{\sum N_{i}}=1,97684$;

$\mu=\frac{1}{t_{c p . o \sigma c .}}=0,5058 u^{-1}$. fully operational vehicles in the specified time period $\Delta t ; N_{i}$ - number of vehicles in full operational order at the beginning of the interval $\Delta t ; N_{i+1}$ - number of vehicles in full operational order at the end of the

The time taken for repairs and servicing performed on the vehicles are recorded in Table 2 . interval $\Delta t$. 
$\frac{\partial P_{0}(t)}{\partial t}=-n \lambda P_{0}(t)+\mu P_{1}(t)$

- the likelihood $P_{i}$ for the system to be in one of its multitude of states before a queue occurs is:

$\frac{\partial P_{i}(t)}{\partial t}=(n-i+1) \lambda P_{i-1}(t)-[(n-i) \lambda+i \mu] P_{i}(t)+\mu(i+1) P_{i+1}(t)$

$i=1 \div m-1$;

- the likelihood $P_{i}$ for the system to be in one of its multitude of states in the presence of a queue is:

$\frac{\partial P_{i}(t)}{\partial t}=(n-i+1) \lambda P_{i-1}(t)-[(n-i) \lambda+m \mu] P_{i}(t)+m \mu P_{i+1}(t)$

$i=m \div n-1$;
- the likelihood $P_{n}$ for the system to be in ta situation in which all channels are employed and all possible orders are waiting in a queue, is:

$\frac{\partial P_{n}(t)}{\partial t}=\lambda P_{n-1}(t)-m \mu P_{n}(t)$.

The numerical solution of differential equations is presented in diagram 1 of the change in the probabilities of the status of the system for technical maintenance of motor vehicles

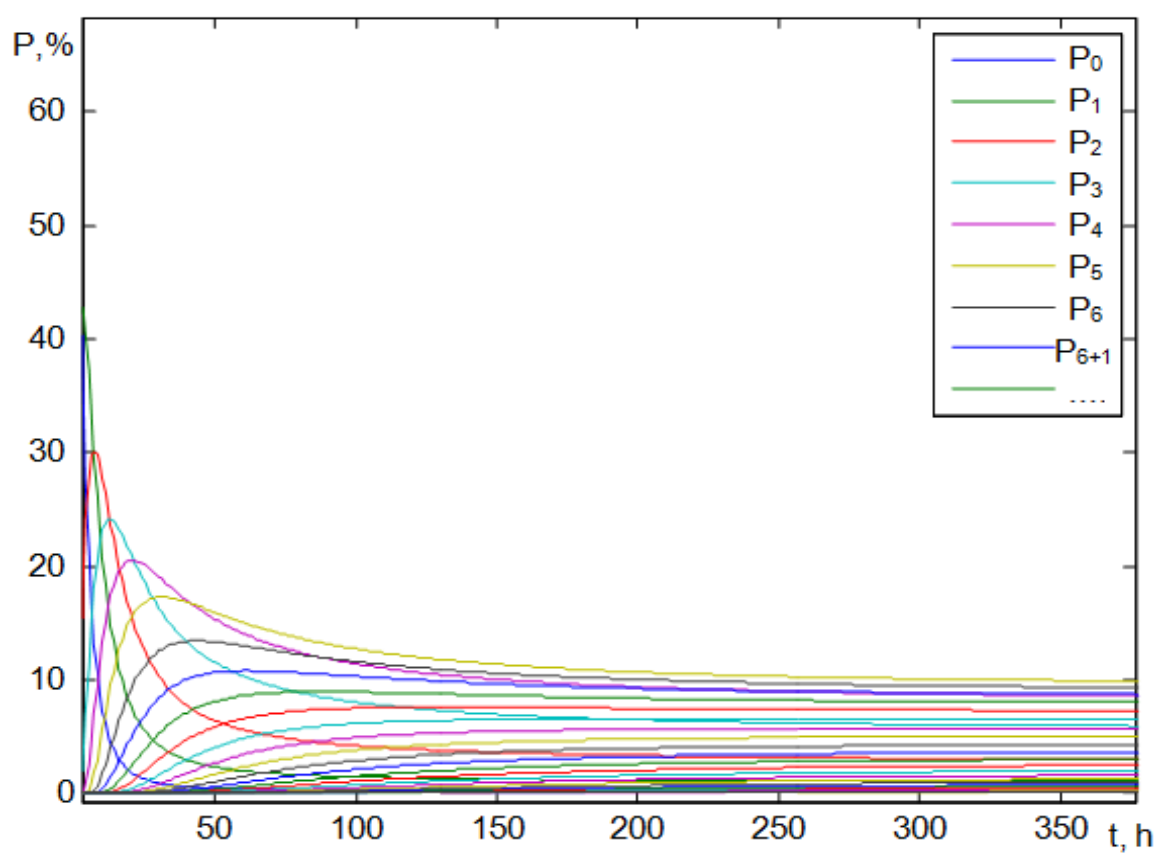

Diagram 1 Change in the probabilities of the states of the system for technical servicing of vehicles as a close queuing system.

The maximum values of the functions and the comparisons between the numerical and analytical values of the probabilities are presented in Table 3.

Table 3 Possible states of the system for technical servicing of vehicles as a close queuing system.

\begin{tabular}{|c|c|c|c|c|c|}
\hline Probability & $\begin{array}{c}\text { Value of } \\
P_{i \max }\end{array}$ & $\begin{array}{c}\text { Time of } \\
P_{i \max }\end{array}$ & $\frac{P_{i \max }-P_{i}}{P_{i}}$ & $\begin{array}{c}\text { Numerical } \\
\text { solution of the } \\
\text { established } \\
\text { value } \mathrm{P}_{\mathrm{i}}\end{array}$ & $\begin{array}{c}\text { Analytical } \\
\text { solution of the } \\
\text { established } \\
\text { value } \mathrm{P}_{\mathrm{i}}\end{array}$ \\
\hline $\boldsymbol{P}_{\boldsymbol{0}}$ & 0,6941 & 1 ч. & 432,8125 & 0,0016 & 0,0016 \\
\hline $\boldsymbol{P}_{\boldsymbol{1}}$ & 0,4270 & 3 ч. & 42,5714 & 0,0098 & 0,0098 \\
\hline $\boldsymbol{P}_{\boldsymbol{2}}$ & 0,3013 & 7 ч. & 9,3540 & 0,0291 & 0,0291 \\
\hline
\end{tabular}




\begin{tabular}{|c|c|c|c|c|c|}
\hline $\boldsymbol{P}_{\boldsymbol{3}}$ & 0,2412 & 13 ч. & 3,2021 & 0,0574 & 0,0573 \\
\hline $\boldsymbol{P}_{\boldsymbol{4}}$ & 0,2047 & 21 ч. & 1,4485 & 0,0836 & 0,0836 \\
\hline $\boldsymbol{P}_{\boldsymbol{5}}$ & 0,1728 & 31 ч. & 0,7963 & 0,0962 & 0,0962 \\
\hline $\boldsymbol{P}_{\boldsymbol{6}}$ & 0,1341 & 43 ч. & 0,4704 & 0,0912 & 0,0912 \\
\hline $\boldsymbol{P}_{\boldsymbol{6}+\boldsymbol{1}}$ & 0,1077 & 61 ч. & 0,2641 & 0,0852 & 0,0852 \\
\hline $\boldsymbol{P}_{\boldsymbol{6}+\mathbf{2}}$ & 0,0890 & 87 ч. & 0,1309 & 0,0787 & 0,0786 \\
\hline $\boldsymbol{P}_{\boldsymbol{6}+3}$ & 0,0753 & 129 ч. & 0,0502 & 0,0717 & 0,0717 \\
\hline $\boldsymbol{P}_{\boldsymbol{6}+4}$ & 0,0651 & 214 ч. & 0,0109 & 0,0644 & 0,0644 \\
\hline $\boldsymbol{P}_{\boldsymbol{6}+\mathbf{5}}$ & 0,0571 & 1200 ч. & 0 & 0,0571 & 0,0571 \\
\hline
\end{tabular}

The indicators for the comparison of the functioning of the system by using

analytical and numerical solutions are displayed in table 4

Table 4 Results of the study of the main parameters of the system for technical servicing of vehicles as a close queuing system.

\begin{tabular}{|c|c|c|}
\hline Indicators for comparison & $\begin{array}{c}\text { Analytical solution in } \\
\text { Microsoft Excel }\end{array}$ & $\begin{array}{c}\text { Numerical solution } \\
\text { in MATLAB }\end{array}$ \\
\hline Probability for the presence of a queue & $P_{\text {queue }}=0,6312$ & $P_{\text {queue }}=0,6312$ \\
\hline $\begin{array}{c}\text { Mathematical expectation of the number of } \\
\text { the number of employed channels }\end{array}$ & $M_{k}=5,3895$ & $M_{k}=5,3895$ \\
\hline $\begin{array}{c}\text { Mathematical expectation of the number of } \\
\text { queuing vehicles }\end{array}$ & $m_{s}=3,6488$ & $m_{s}=3,6486$ \\
\hline Average time for queuing per order & $\bar{t}_{\text {wait }}=1,2855 \mathrm{~h}$. & $\bar{t}_{\text {wait }}=1,2855 \mathrm{~h}$. \\
\hline Load coefficient per servicing channel & $\Delta T=0,8983$ & $\Delta T=0,8983$ \\
\hline
\end{tabular}

The numerical solution of differential equations makes it possible to determine the mathematical expectations of the number of employed channels - presented in diagram 2 and the mathematical expectation of the number of orders waiting in queue - in diagram 3 as functions of time.

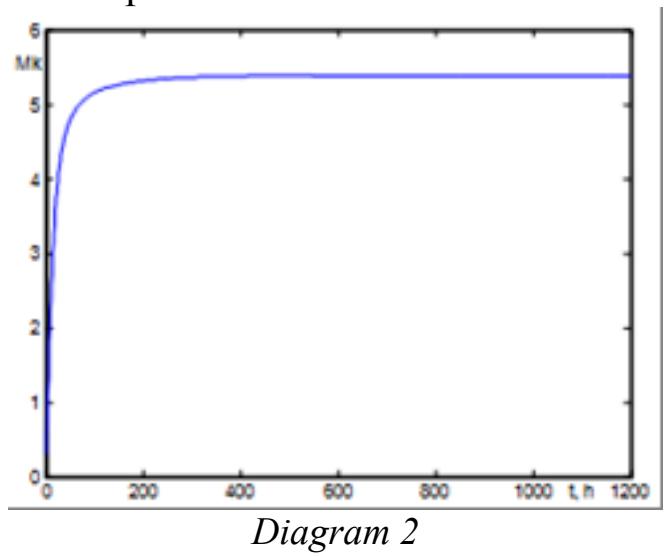

Change in the mathematical expectation of the number of employed channels - $M_{k}$ of the system for technical servicing of vehicles as a close queuing system. 


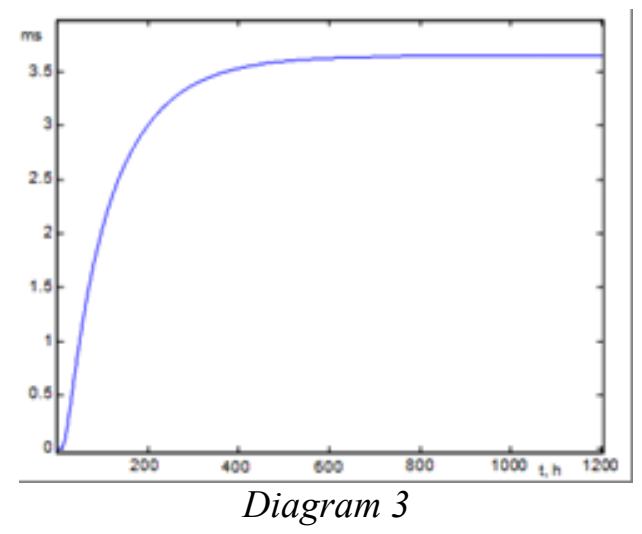

Change in the mathematical expectation of the number of queuing vehicles - $m_{s}$ of the system for technical servicing of vehicles as a close queuing system.

\section{Conclusions:}

1. The analysis of the results obtained in the study shows that the system goes from its original dynamic state to a stationary mode, progressively reaching its maximum values and gradually going into stationary mode.

2. The comparison of the results of the analytical and the numerical solution of differential equations shows a minimum percentage of error, which proves their authenticity.

3. The graph of the probability of the conditions for one to five employed channels has a clearly defined maximum, while the rest either increase or decrease (for $\mathrm{P}_{0}$ ) asymptotically.
4. The duration of the transitional mode is up to $8 \%$ of the entire period under consideration.

5. Mathematical expectation of the number of employed channels $-M_{k}$, and the length of the queue $-m_{s}$ increase asymptotically through the unsettled mode of operation of the system until settling on the established values - respectively 5.39 employed channels, 3,65 orders in queue, and a load coefficient of $89 \%$ per channel, which are indirect indicators of the optimum load on the system.

[1] ZIL 131 army truck and its modifications. Operating Instructions, Military Publishing House, Sofia-1985.

[2] Vassilev H.,Tsanov L. et al. Applied Mathematics, Military Publishing House, Sofia, 1985

[3] Grigorov D, et al. Research into operations, Military Publishing House, Sofia 1975

[4] Logbook for the receipt of material resources for repair/1 December 2004-30 April 2005 Documentation of Section S-4 of 4th infantry battalion of the stabilization forces in the Republic of Iraq, Formation 34750 Karlovo, 2005

[5] Lilov. I. Quantitative methods in transport logistics, National Military University "Vasil Levski" V. Tarnovo, 2006.

[6] Monthly travel records of armoured vehicles. 1 December 2004-30 April 2005 Documentation of Section S-4 of 4th infantry battalion of the stabilization forces in the Republic of Iraq, Formation 34750 Karlovo, 2005

[7] Mitkov At., Minkov D. Mathematical methods of engineering calculations Rousse 1985

[8] Ordinance on the technical operation of armoured vehicles and other transport machines in the Bulgarian Army, Military Publishing House EOOD Sofia 1999

[9] UAZ - 469 Manual for maintenance and repair, Military Publishing House, Sofia1989 